\title{
Satellite Image Classification Methods and Techniques: A Review
}

\author{
Sunitha Abburu, PhD \\ Dept. of Computer Applications \\ Adhiyamaan College of Engineering \\ Hosur, Tamilnadu, India.
}

\author{
Suresh Babu Golla \\ Dept. of Computer Applications \\ Adhiyamaan College of Engineering \\ Hosur, Tamilnadu, India.
}

\begin{abstract}
Satellite image classification process involves grouping the image pixel values into meaningful categories. Several satellite image classification methods and techniques are available. Satellite image classification methods can be broadly classified into three categories 1) automatic 2) manual and 3 ) hybrid. All three methods have their own advantages and disadvantages. Majority of the satellite image classification methods fall under first category. Satellite image classification needs selection of appropriate classification method based on the requirements. The current research work is a study on satellite image classification methods and techniques. The research work also compares various researcher's comparative results on satellite image classification methods.
\end{abstract}

\section{Keywords}

Satellite Image, Classification, Summary of reviews

\section{INTRODUCTION}

Satellite images are rich and plays a vital role in providing geographical information [1]. Satellite and remote sensing images provides quantitative and qualitative information that reduces complexity of field work and study time [2]. Satellite remote sensing technologies collects data/images at regular intervals. The volumes of data receive at datacenters is huge and it is growing exponentially as the technology is growing at rapid speed as timely and data volumes have been growing at an exponential rate [3]. There is a strong need of effective and efficient mechanisms to extract and interpret valuable information from massive satellite images. Satellite image classification is a powerful technique to extract information from huge number of satellite images.

Satellite image classification is a process of grouping pixels into meaningful classes [4]. It is a multi-step workflow. Satellite image classification can also be referred as extracting information from satellite images. Satellite image classification is not complex, but the analyst has to take many decisions and choices in satellite image classification process. Satellite image classification involves in interpretation of remote sensing images, spatial data mining, studying various vegetation types such as agriculture and foresters etc. and studying urban and to determine various land uses in an area [5].
The current research work is a literature review on satellite image classification methods and techniques. It describes and provide details on various satellite image classification methods to the analyst. The current literature review emphasis on automated satellite image classification methods and techniques.

The rest of the paper is organized as follows. Section 2 gives need of the satellite image classification, section 3 illustrates various satellite image classification techniques, section 4 discusses few recent satellite image classification methods and section 5 concludes.

\section{NEED OF SATELLITE IMAGE CLASSIFICATION}

Satellite image classification plays a major role in extract and interpretation of valuable information from massive satellite images. Satellite image classification is required for:

- $\quad$ Spatial data mining [6]

- Extract information for an application

- Thematic map creation

- Visual and digital satellite image interpretation

- $\quad$ Field surveys

- $\quad$ Effective decision making

- Disaster management

\section{SATELLITE IMAGE TECHNIQUES}

There are several methods and techniques for satellite image classification. Figure 1 shows hierarchy of satellite image classification methods. Satellite image classification methods can be broadly classified into three categories [7]:

- $\quad$ Automated

- Manual

- Hybrid

\subsection{Automated}

Automated satellite image classification methods uses algorithms that applied systematically the entire satellite image to group pixels into meaningful categories. Majority of the classification methods fall under this category. Automated satellite image classification methods further classified into two categories 1) supervised 2) unsupervised classification methods. 


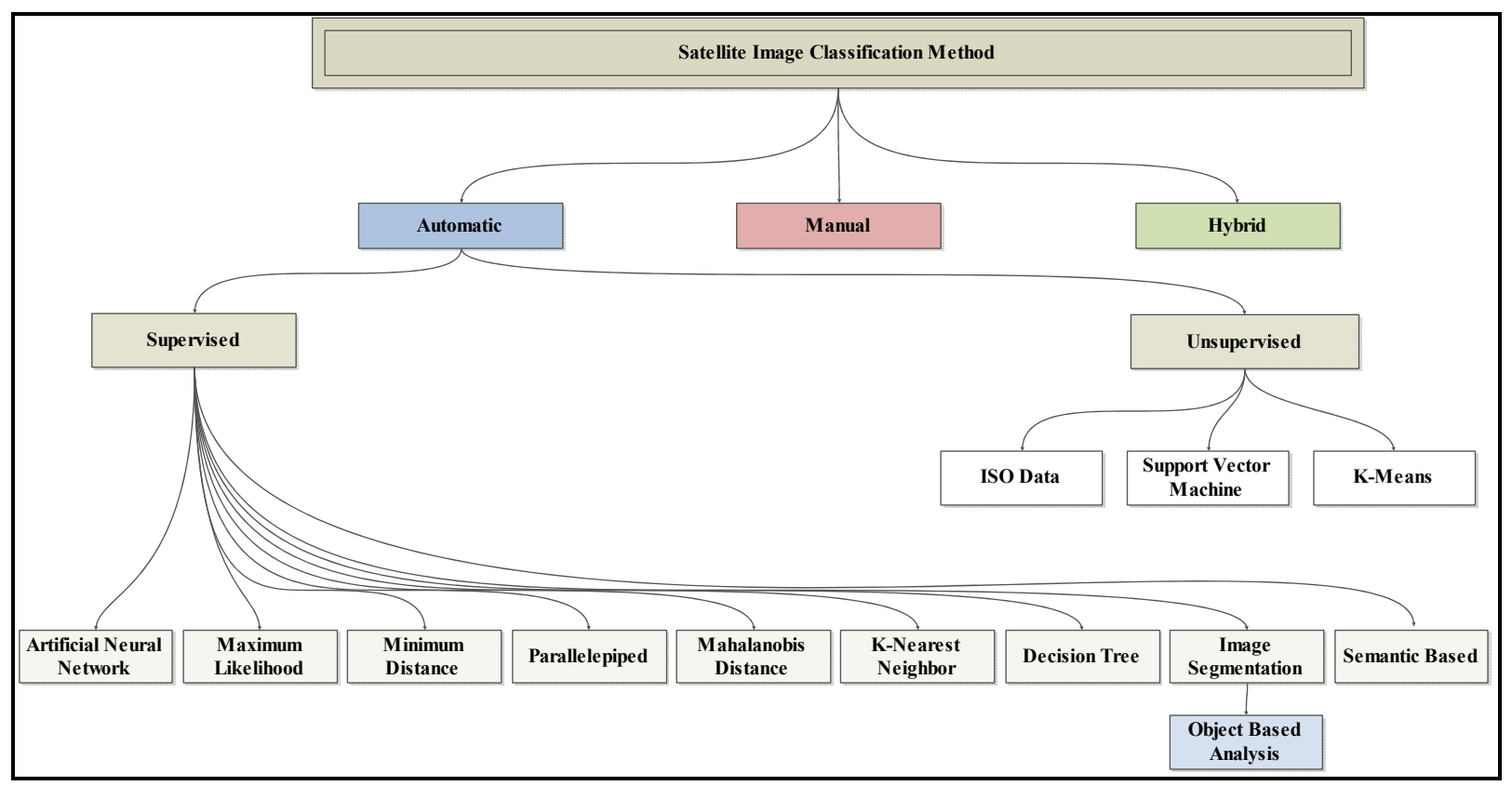

Figure. 1. Satellite image classifications methods hierarchy

\subsection{Supervised}

Supervised classification methods require input from an analyst. The input from analyst is known as training set. Training sample is the most important factor in the supervised satellite image classification methods. Accuracy of the methods highly depends on the samples taken for training. Training samples are two types, one used for classification and another for supervising classification accuracy.
Figure 2 Shows supervised satellite image classification process. Training set is provided before classification is run. Major supervised classification methods uses the following statistical techniques:

- Artificial Neural Network (ANN)

- Binary Decision Tree (BDT)

- Image Segmentation

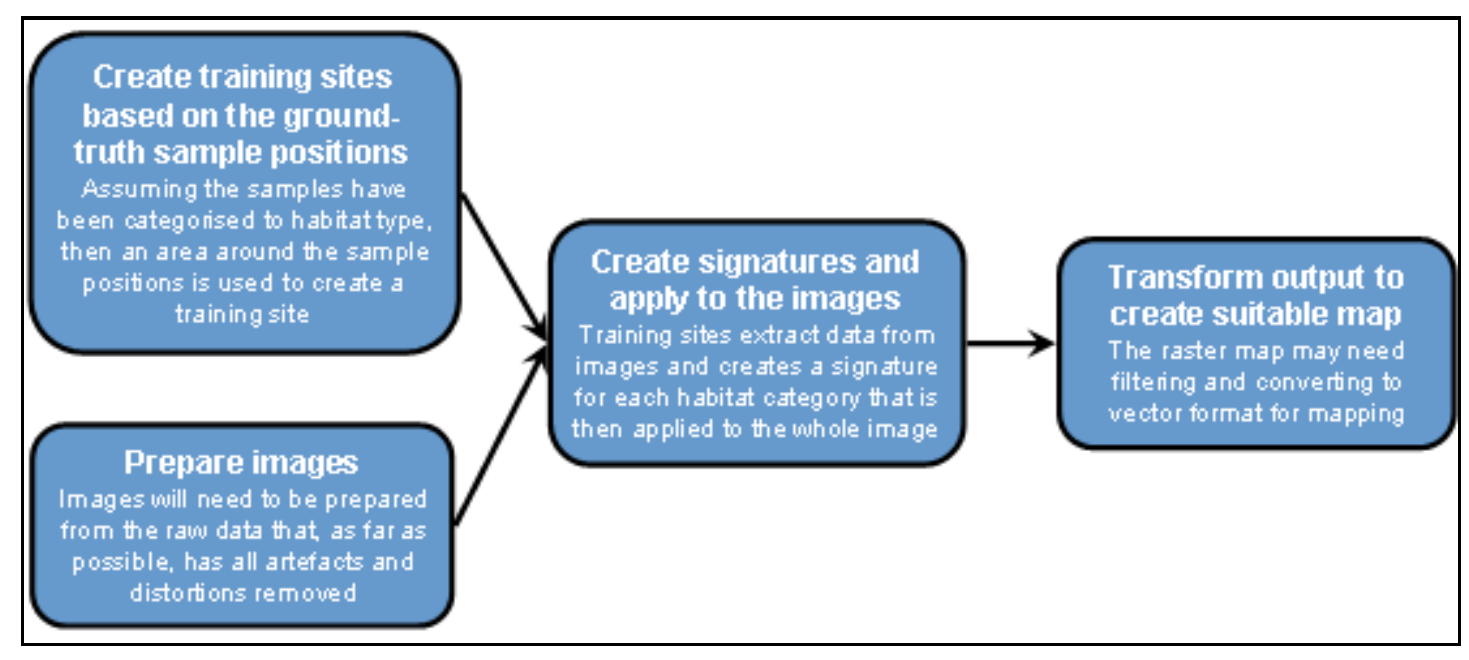

Figure. 2. Supervised satellite image classification process.

Various classification techniques deals with different kinds of similarity matching methods. Supervised classification includes additional functionality such as analyzing input data, creating training samples and signature files, and determining the quality of the training samples and signature files.

Artificial Neural Network: Algorithms fall under Artificial Neural Network (ANN) simulate human learning process to associate the correct meaningful labels to image pixels. Advantage of ANN based satellite image classification algorithms is easy to incorporate supplementary data in the classification process and improves classification accuracy.
Binary Decision Tree: Binary Decision Tree (BDT) satellite image classification algorithms are machine learning techniques. Decision tree technique includes a set of binary rules that define meaningful classes to be associated to individual pixels. Different decision tree software are available to generate binary rules. The software takes training set and supplementary data to define effective rules.

Image Segmentation: Segmentation plays a vital role in satellite image processing, analysis and pattern recognition [8]. Satellite image segmentation techniques/algorithms are not directly related to image classification. Image 
segmentation groups pixels which are relatively homogeneous into segments. Image segmentation algorithms provide variables that support analyst to specify relative size and shape of the segments. Segmented image can be classified at segmentation level, instead of pixel level. Segmentation level satellite image classification algorithms are much faster than pixel level classification methods.

\subsection{Unsupervised}

Unsupervised classification technique uses clustering mechanisms to group satellite image pixels into unlabeled classes/clusters. Later analyst assigns meaningful labels to the clusters and produces well classified satellite image. Most common unsupervised satellite image classification is ISODATA [9], Support Vector Machine (SVM) and K-Means [10].

\subsection{Manual}

Manual satellite image classification methods are robust, effective and efficient methods. But manual methods consume more time. In manual methods the analyst must be familiar with the area covered by the satellite image. Efficiency and accuracy of the classification, depends on analyst knowledge and familiarity towards the field of study.

\subsection{Hybrid}

Hybrid satellite image classification methods combines the advantages of automated and manual methods. Hybrid approach uses automated satellite image classification methods to do initial classification, further manual methods are used to refine classification and correct errors.

\section{SATELLITE IMAGE CLASSIFICATION METHODS}

This section illustrates few recent satellite image classification methods.

J. Shabnam et al., [11] introduced supervised satellite image classification method to classify very high resolution satellite images into specific classes using fuzzy logic. This method classifies satellite images into five major classes: shadow, vegetation, road, building and bare land. This method uses image segmentation and fuzzy techniques for satellite image classification. It applies two levels of segmentation, first level segmentation identifies and classifies shadow, vegetation and road. Second level segmentation identifies buildings. Further it uses contextual check to classify unclassified segments and regions. Fuzzy techniques are used to improve the classification accuracy at the borders of objects.

[12] Presents a supervised satellite image classification method to determine water, urban and green land on satellite images. This method takes training set for every class and computes threshold value using k-means and LDA [13] techniques. The method extracts low-level features from satellite images and applies k-means algorithm to group into unlabeled clusters. Meaningful labels are assigned to the unlabeled classes by comparing threshold values with extracted features.

[14] Describes ontology based supervised ocean satellite image classification method. This method illustrates power of ontology in ocean satellite image classification. The method extracts low level features from ocean satellite images and represent in owl file format. This owl file is merged with domain ontologies and labeling rules. Labeling rules, training rules, binary decision tree rules and expert rules are represent using SWRL [15] language. The method produces classification results of given ocean satellite image with the support of training, human expert, decision support and labeling rules. [14] Also provides a tool as plug-in for protégé ontology editor. The tool supports ocean satellite images with the support of domain ontologies.

S. Muhammad et al., [1] proposed a supervised satellite image classification method using decision tree technique. This method extracts features from satellite image based on pixel color and intensity. Extracted features assist to determine objects reside in the satellite images. The methods classifies satellite images using decision tree with the support of identified objects.

[16] Presents a method for the classification of satellite images into multiple predefined land cover classes. This method is automated and uses segment level classification with the support of training set. The classification methods includes contextual properties of predefined multiple classes to improve the classification accuracy.

A. Selim [17] proposed a classification method using Bayesian technique. The method uses spatial information for classification of high-resolution satellite images. The method perform classification in two phases. Phase 1: spectral and textural features are extracted for each pixel to train Bayesian classifiers with discrete non-parametric density models. Phase 2: iterative split-and-merge algorithm is used to convert the pixel level classification maps into contiguous regions.

ISODATA [9] technique is most common unsupervised satellite classification method. It creates predefined number of unlabeled clusters/classes in a satellite image. Later meaningful labels are assigned to the clusters. ISODATA parameters needs several parameters that control number of clusters and iterations to be run. In few cases clusters may contain pixels of different classes. In such situations ISODATA uses cluster-busting [18] technique to label the complex classes.

$\mathrm{K}-\mathrm{Means}[10]$ is a popular statistics and data mining technique. It partitions $\mathrm{n}$ observations into $\mathrm{k}$ clusters based on Euclidean mean value. Advantages with the K-Means technique are simple to process and fast execution. Limitation with this method is analyst should know priori number of classes.

Support Vector Machine (SVM) [19] is a non- parametric unsupervised statistical classification method. This method can be used to extract land-use map. SVM works on the assumption that there is no information on how to distribute the overall data. SVM reduces satellite classification cost, increases speed and improves accuracy.

Minimum distance [20] approach calculates mean spectra of each predefined class and assigns the pixel to a group that has the least distance to mean. It easy to execute and simple to process. But minimum distance method considers only mean value. Mahalanobis distance method [21] is very similar to minimum distance method. It uses statistics technique covariance matrix for satellite image classification.

Parallelepiped [20] executes based on parallelepiped-shaped boxes for each class. Parallelepiped boundaries for each class are pre-determined. Pre-determined boundaries identifies checks pixels of test images and determine class of the pixel. Parallelepiped method is fast and easy to run, but overlap may produce false results.

Maximum likelihood [22] method is a statistical supervised approach for recognizing the patterns. It allocates pixels to 
appropriate classes based on probability values of the pixels. Maximum likelihood is an efficient method to classify pixels of satellite image. But it is time consuming and insufficient ground truth data produces poor results.

\section{COMPARISON OF SATELLITE IMAGE CLASSIFICAIOTN METHODS}

Various researchers have been performed comparison on unsupervised, supervised satellite image classification methods and on the combination of both with respect to classification accuracy and kappa coefficient. This section compares comparison summary of various researchers. Table 1 provides comparison summary of different researcher's conclusion. From the comparison summary, researcher's opinion on better satellite image classification method is not consistent. Further there is a need to study weather satellite image classification methods performance depends on test dataset.

Table 1. Comparison of various researchers satellite image classification comparative statements

\begin{tabular}{|c|c|c|c|}
\hline Researcher & $\begin{array}{l}\text { Classification Methods } \\
\text { Taken for Comparison }\end{array}$ & Test Data & $\begin{array}{l}\text { Better Method from the } \\
\text { Researcher Study }\end{array}$ \\
\hline K. Kanika et al., [23] & $\begin{array}{l}\text { K-Nearest Neighbour } \\
\text { Minimum Distance } \\
\text { Maximum Likelihood }\end{array}$ & IRIS Plants Dataset & K-Nearest Neighbour \\
\hline R. Offer et al., [24] & $\begin{array}{l}\text { ISODATA } \\
\text { Maximum Likelihood } \\
\text { Hybrid Method }\end{array}$ & Desert Outlay Datasets & Hybrid Method \\
\hline A. Aykut et al., [25] & $\begin{array}{l}\text { Maximum Likelihood } \\
\text { Minimum Distance } \\
\text { Parellelpiped }\end{array}$ & Landsat 7 ETM+ Images & Maximum Likelihood \\
\hline T. Jamshid et al., [26] & $\begin{array}{l}\text { Parallelepiped } \\
\text { Minimum Distance } \\
\text { Chain Method }\end{array}$ & Landsat 5TM images & Chain Method \\
\hline H. N. Shila et al., [27] & $\begin{array}{l}\text { Unsupervised } \\
\text { Supervised } \\
\text { Hybrid Method }\end{array}$ & Landsat7 ETM+ data & Hybrid Method \\
\hline N. Maryam et al., [28] & $\begin{array}{l}\text { Support Vector Machine } \\
\text { Maximum Likelihood } \\
\text { Mahalanobis Distance } \\
\text { Minimum Distance, Spectral } \\
\text { Information Divergence } \\
\text { Binary Codes } \\
\text { Parallelepiped }\end{array}$ & Landsat7 ETM+ data & Support Vector Machine \\
\hline $\begin{array}{l}\text { Manoj Pandya et al., } \\
\text { [29] }\end{array}$ & $\begin{array}{l}\text { K-Means } \\
\text { ISODATA } \\
\text { Minimum Distance } \\
\text { Maximum Likelihood } \\
\text { Parallelpiped } \\
\text { Seeded region Growing } \\
\text { Enhanced Seeded region } \\
\text { Growing } \\
\end{array}$ & $\begin{array}{l}\text { Landsat, SPOT and IRS } \\
\text { Datasets }\end{array}$ & $\begin{array}{l}\text { Enhanced Seeded Region } \\
\text { Growing }\end{array}$ \\
\hline T. Subhash et al., [30] & $\begin{array}{l}\text { Maximum Likelihood } \\
\text { Minimum Distance } \\
\text { Mahalanobis Distance } \\
\end{array}$ & Landsat7 ETM+ data & Maximum Likelihood \\
\hline $\begin{array}{l}\text { W. Malgorzata et al., } \\
\text { [31] }\end{array}$ & $\begin{array}{l}\text { Pixel-based Classification } \\
\text { Object-Oriented Classification }\end{array}$ & $\begin{array}{l}\text { Multi-Spectral Satellite } \\
\text { Images }\end{array}$ & Object-Oriented Classification \\
\hline
\end{tabular}

\section{CONCLUSION}

This paper gives a summary on automated satellite image classification methods and compares several reviews done by various researchers. Automated satellite image classification methods can be classified into 1) supervised 2) unsupervised. Supervised and unsupervised satellite image classification methods differ in the way of grouping pixels into meaningful categories. In the literature, researchers have presented survey on satellite image classification methods and evaluated the performance against different datasets. This paper summarizes the various reviews on satellite image classification methods and techniques. The summary helps researchers to select appropriate satellite image classification method or technique based on the requirements.

\section{ACKNOWLEDGMENTS}

The study presented in this paper is done as part of a sponsored project founded by Indian Space Research Organization (ISRO-RESPOND), India. The authors would like to express their sincere thanks to ISRO for providing the support. 


\section{REFERENCES}

[1] Muhammad, S., Aziz, G., Aneela, N. and Muhammad, S. 2012. "Classification by Object Recognition in SatelliteImages by using Data Mining". In Proc. Proceedings of the World Congress on Engineering (WCE 2012), Vol I, July 4 - 6, London, U.K.

[2] Chaichoke, V., Supawee, P., Tanasak, V. and Andrew, K, S. 2011. "A Normalized Difference Vegetation Index (NDVI) Time-Series of Idle Agriculture Lands: A Preliminary Study", Engineering Journal. Vol. 15, Issue 1, pp. 9-16.

[3] Zheng, X., Sun, X., Fu, K. and Hongqi Wang, 2013. "Automatic Annotation of Satellite Images via Multifeature Joint Sparse Coding With Spatial Relation Constraint", IEEE Geoscience and Remote Sensing Letters, VOL. 10, NO. 4, JULY 2013, pp.652-656.

[4] Anders Karlsson, 2003. "Classification of high resolution satellite images", August 2003, available at http://infoscience.epfl.ch/record/63248/files/TPD_Karlss on.pdf.

[5] Amanda Briney, 2014. "An Overview of Remote Sensing", May 16, 2014. [online] available at http://geography.about.com/od/geographictechnology/a/r emotesensing.htm

[6] Soliman, O, S. and Mahmoud, A.S., 2012. "A classification system for remote sensing satellite images using support vector machine with non-linear kernel functions", In proc. 8th International Conference on Informatics and Systems (INFOS), IEEE, 14-16 May 2012, pp.BIO-181,BIO-187, Cairo.

[7] Horning, N. 2004. "Land cover classification methods", Version 1.0. American Museum of Natural History, Center for Biodiversity and Conservation. Available at http://biodiversityinformatics.amnh.org.

[8] Murugeswari, P. and Manimegalai, D. 2012. "Color Textured Image Segmentation Using ICICM - Interval Type-2 Fuzzy C-means Clustering Hybrid Approach", Engineering Journal, Vol. 16, No. 5, pp. 115-126.

[9] Al-Ahmadi, F, S. and Hames, A, S. 2009. "Comparison of Four Classification Methods to Extract Land Use and Land Cover from Raw Satellite Images for Some Remote Arid Areas, Kingdom of Saudi Arabia”, Journal of King Abdulaziz University-Earth Sciences, Vol. 20, No.1, pp: 167-191.

[10] Ahmed, R., Mourad, Z., Ahmed, B, H. and Mohamed, B. 2009. "An Optimal Unsupervised Satellite image Segmentation Approach Based on Pearson System and kMeans Clustering Algorithm Initialization”, International Science Index, Vol. 3, No. 11, pp. 948-955.

[11] Shabnam Jabari and Yun Zhang, 2013. “ Very High Resolution Satellite Image Classification Using Fuzzy Rule-Based Systems", Algorithms, vol.6, no.4, pp. 762781.

[12] Chandrakala, M. and Amsaveni, R. 2013. "Classification of Remote Sensing Image Areas Using Surf Features and Latent Dirichlet Allocation", International Journal of
Advanced Research in Computer Science and Software Engineering, Vol. 3, Issue 9, pp. 178-182.

[13] David M. Blei, Andrew Y. and Michael I, J. 2003. "Latent dirichlet allocation", The Journal of Machine Learning Research, ACM, Volume 3, pp. 993-1022.

[14] Jesus, M., Almendros-Jiménez., Luis Domene., and José A. Piedra-Fernández, 2013. "A framework for Ocean Satellite Image Classification Based on Ontologies", IEEE Journal of Selected Topics in Applied Earth Observations and Remote Sensing, VOL. 6, NO. 2, APRIL 2013, pp. 1048-1063.

[15] Martin Kuba, "OWL 2 and SWRL Tutorial" [online] available at http://dior.ics.muni.cz/ makub/owl/.

[16] Bjorn Frohlich., Eric Bach., Irene Walde., Soren Hese., Christiane Schmullius, and Joachim Denzler. 2013. "Land Cover Classification of Satellite Images using Contextual Information", ISPRS Annals of the Photogrammetry, Remote Sensing and Spatial Information Sciences, Volume II-3/W1, pp. 1-6.

[17] Selim Aksoy. 2006. "Spatial Techniques for Image Classification," in C. H. Chen, ed., Signal and Image Processing for Remote Sensing, CRC Press, pp.491-513.

[18] Hurd, J.D., Civco, D, L., Gilmore, M., Prisloe, L. and Wilson, E. 2006. "Tidal wetlandclassification from Landsat imagery using an integrated pixel-based andobject-based classification approach". In Proc. 2006 ASPRS Annual Convention, Reno.

[19] Jensen, J, R. 2005. "Introductory Digital Image Processing: A Remote Sensing Perspective", 3rd Edition, Up-per Saddle River: Prentice-Hall, 526 p.

[20] Tso, B. and Mather, P, M. 2009. "Classification Methods for Remotely Sensed Data", 2nd Ed. Chapter 2-3, Taylor and Francis Group, America.

[21] Richards, J, A. 2013. "Remote Sensing Digital Image Analysis", Springer-Verlag, Berlin, 5th Ed. 496 p.

[22] Munyati, C. H. "Use of Principal Component Analysis (PCA) of Remote Sensing Images in Wetland Change Detection on the Kafue Flats, Zambia", Geocarto Int Vol.19, No.3, PP.11-22.

[23] Kanika, K., Anil, K, G. and Rhythm, G. 2013. "A Comparative Study of Supervised Image Classification Algorithms for Satellite Images", International Journal of Electrical, Electronics and Data Communication, Vol. 1, Issue 10, pp. 10-16.

[24] Offer, R. and Arnon, K. 2011. "Comparison of Methods for Land-Use Classification Incorporating Remote Sensing and GIS Inputs", EARSeL eProceedings, Vol. 10, No. 1, pp. 27-45.

[25] Aykut, A., Eronat, A, H. and Necdet, T. 2004. "Comparing Different Satellite Image Classification Methods: An Application in Ayvalik District, Western Turkey",In Proc. XXth ISPRS Congress Technical Commission, ISPRS, Vol. XXXV Part B4, July 12-23, Istanbul, Turkey. 
[26] Jamshid, T., Nasser, L. and Mina, F. 2013. "Satellite Image Classification Methods and Landsat 5tm Bands", Cornell University Library.

[27] Shila, H, N. and Ali, R, S. 2010. "Comparison of Land Covers Classification Methods in Etm+ Satellite Images (Case Study: Ghamishloo Wildlife Refuge)", Journal of Environmental Research and Development, Vol. 5, No. 2, pp. 279-293.

[28] Maryam, N., Vahid, M, Z. and Mehdi, H. 2014. "Comparing different classifications of satellite imagery in forest mapping (Case study: Zagros forests in Iran)", International Research Journal of Applied and Basic Sciences, Vol. 8, No. 7, pp. 1407-1415.

[29] Manoj, P., Astha, B., Potdar, M, B., Kalubarme, M, H. and Bijendra, A. 2013. "Comparison of Various
Classification Techniques for Satellite Data", International Journal of Scientific \& Engineering Research, Vol. 4, Issue 2, pp. 1-6.

[30] Subhash, T., Akhilesh, S. and Seema, S. 2012. "Comparison of Different Image Classification Techniques for Land Use Land Cover Classification: An Application in Jabalpur District of Central India", International Journal of Remote Sensing and GIS, Vol. 1, Issue 1, pp. 26-31.

[31] Malgorzata, V, W., Anikó, K. and rzsébet, V. 2012. "Comparison of Different Image Classification Methods in Urban Environment", In Proc. International Scientific Conference on Sustainable Development \& Ecological Footprint, March 26-27 2012, Sopron, Hungary. 